\title{
Esophageal lymphangioma: a case report and review of literature
}

Yuqing Cheng ${ }^{1}$, Xiaoli Zhou' ${ }^{1}$ Kequn $X u^{2}$ and Qin Huang ${ }^{1,3^{*}}$

\begin{abstract}
Background: Lymphangioma of the esophagus is an exceedingly rare benign tumor. Herein, we reported a case of lymphangioma in the thoracic esophagus.

Case presentation: The patient was a 48-year-old woman who presented to our hospital with a one-month history of dysphagia. Upper endoscopy revealed an esophageal submucosal lesion that was completely removed by endoscopic submucosal dissection. Pathologic examination of the resected specimen secured the diagnosis of lymphangioma. A review of the PUBMED indexed literature in English with the key words of esophagus and lymphangioma was carried out and the results were discussed.

Conclusion: Esophageal lymphangioma is a rare submucosal tumor and should be included in the differential diagnosis of esophageal submucosal tumors.
\end{abstract}

Keywords: Lymphangioma, Esophagus, Endoscopic submucosal dissection

\section{Background}

Lymphangioma is a benign microcystic lymphovascular lesion characterized by dilated lymphatic channels, and located primarily in the neck, axilla, and groin, as reported in the literature [1]. Lymphangioma rarely occurs in the esophagus [2]. The present report described a patient presented with dysphagia. Subsequent upper endoscopy discovered a broad-based, sessile, elevated submucosal esophageal lesion that was successfully resected endoscopically. Pathologic evaluation of the resected lesion disclosed the evidence for lymphangioma. In this case report, we analyzed the characteristics of white-light endoscopic appearances, endoscopic ultrasonography (EUS) signs, endoscopic resection, and histopathologic features of this benign tumor with a review of the relevant literature.

\section{Case presentation}

A 48-year-old woman complained of dysphagia for 1 month. In April 2018, she underwent esophagogastroduodenoscopy

\footnotetext{
* Correspondence: qinhuang0122@gmail.com

'Department of Pathology of the Affiliated Changzhou Second People's Hospital of Nanjing Medical University, Changzhou, China

${ }^{3}$ Department of Pathology and Laboratory Medicine of Veterans Affairs Boston Healthcare System, Harvard Medical School and Brigham and Women's Hospital, 1400 VFW Parkway, West Roxbury, MA 02132, USA Full list of author information is available at the end of the article
}

in our hospital and an esophageal submucosal tumor (SMT) was discovered in the upper-mid esophagus about $22-24 \mathrm{~cm}$ from the incisors. Under white light endoscopy, this lesion was broad-based, poorly defined, sessile, and elevated in size of $1.5 \mathrm{~cm}$ in diameter. The overlying mucosal surface was pale-whitish gray without ulcer or erosion (Fig. 1a). The adjacent esophageal mucosa was normal. There was no evidence of simon-red mucosal metaplastic changes. No additional tumor was identified. The stomach and duodenum were normal. Further endoscopic evaluation of this esophageal lesion with endoscopic ultrasonography (EUS) demonstrated a hypoechoic mass with heterogeneous echo and microcystic features; signs for blood flow were absent. The lesion was located primarily in the submucosal space without involvement of the underlying esophageal muscularis propria (Fig. 1b). This submucosal lesion was considered clinically as a benign lesion that was completely resected by endoscopic submucosal dissection (ESD) for histopathologic diagnosis and to relieve the patient's symptoms.

The resected lesion measured $1.5 \times 1.2 \times 1.0 \mathrm{~cm}$ in size and exhibited whitish-gray, polypoid gross appearances. After routine formalin fixation, the lesion was serially sectioned to show whitish-gray, soft and vaguely spongy cut surface. No solid tumor or nodule was noted. No necrosis/hemorrhage was identified. Microscopically, the lesion involved both lamina propria and submucosa, but 


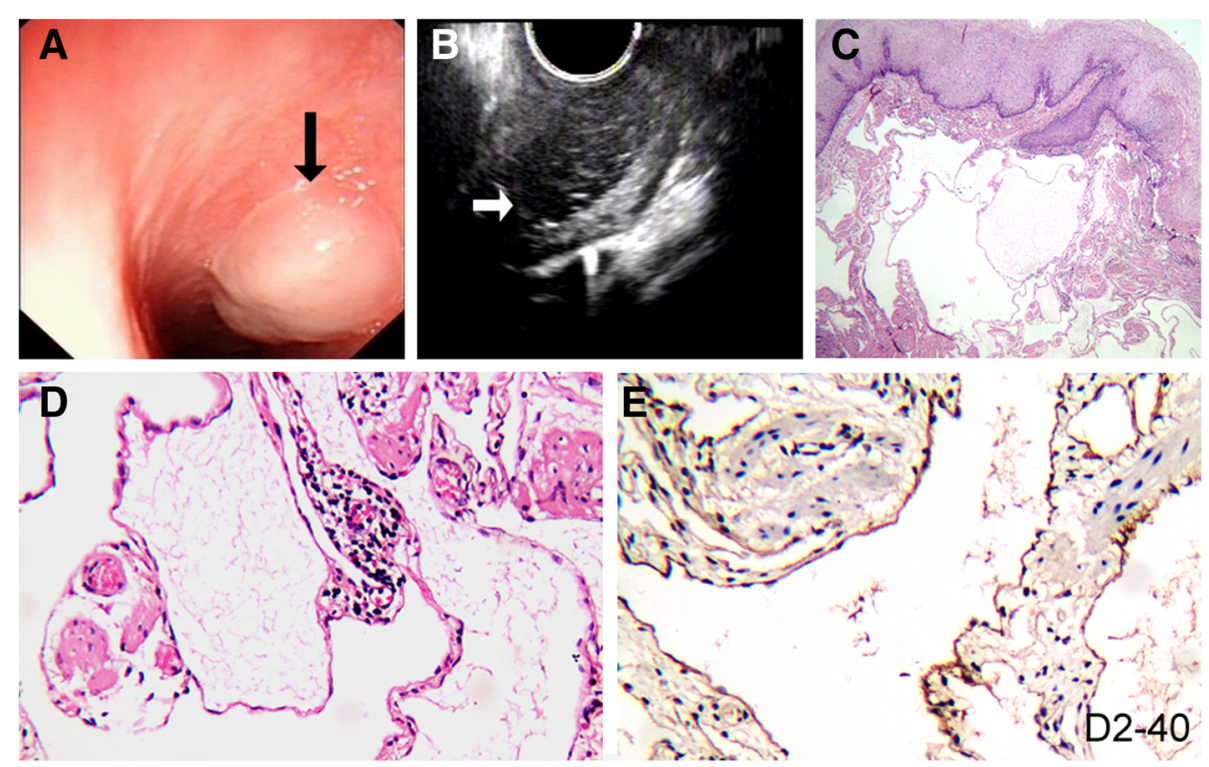

Fig. 1 Endoscopic and histopathological findings of the esophageal lymphangioma. a sessile polypoid soft tumor with a lustrous surface was found endoscopically in the upper-mid esophagus at 20-22 cm from the incisor. $\mathbf{b}$ Under endoscopic ultrasonography, the tumor showed a heterogeneous hypoechoic pattern and involved the lamina propria and submucosal space, but not the muscularis propria. c Microscopically, the tumor was composed of dilated lymphatic vessels in various sizes underneath the normal esophageal squamous epithelium. $\mathbf{d}$ The lymphatic vessels were lined by flat benign endothelial cells with lymphocytic aggregates in the fibrous stroma. e Flat endothelial lining cells of this esophageal lymphangioma were immunoreactive to D2-40, a classical biomarker for lymphatic endothelial cells, confirming the diagnosis of lymphangioma

not muscularis propria, and was composed of thinwalled, micro-cystically dilated lymphatic channels in various sizes, which were separated by delicate fibrous stroma (Fig. 1c). The lymphatic channels were lined by flat endothelial cells with occasional small lymphocytic aggregates present between channels (Fig. 1d). Within some lymphatic channels was amorphous lymphoid fluid. Hemosiderin deposition and blood vessels invested by smooth-muscle layers were absent. No dysplasia or malignancy was identified in the tumor or the overlying squamous epithelium. By immunohistochemistry with valid controls, the lymphatic channel lining cells exhibited diffuse immunopositivity for D2-40 (Fig. 1e), but focal positivity for CD34, and negativity for FVIII.

The patient post-ESD hospital course was uneventful. She was well at a 12-month follow-up without complaints.

\section{Discussion and conclusions}

Lymphangioma is a benign soft tissue tumor that rarely occurs in the gastrointestinal tract in adults [3]. About 1\% of lymphangiomas were originated in the gastrointestinal tract, of which the most frequent location was the colon, followed by the stomach, duodenum, small intestine, and esophagus [2]. A PUBMED literature search identified only 30 cases of esophageal lymphangioma in English (Table 1). Although there is no evidence of increased incidence of this tumor, the detection of esophageal lymphangioma increased over the past decade with 14 cases reported, compared to merely 16 cases published over 70 years after its initial identification in 1934 [4], suggesting an increased use of upper endoscopy and awareness of endoscopists on esophageal lesions.

Lymphangioma in the esophagus, unlike its counterpart in the gastrointestinal mesentery or head and neck region, tends to occur in adulthood, with the median and average age of 55 and 53.8 years (range 32-72), respectively. The male:female ratio is about $2.6(21: 8)$. In general, Esophageal lymphangioma is solitary in most reported cases $(93.1 \%, 27 / 29)$, but multiple tumors $(6.9 \%$, $2 / 29$ ) do occur. Although the tumor has a wide range in size, from $0.4 \mathrm{~cm}$ to $16 \mathrm{~cm}$, the size of most tumors $(74.1 \%, 20 / 27)$ is less than $5 \mathrm{~cm}$ with overall median and average sizes of $1.9 \mathrm{~cm}$ and $3.2 \mathrm{~cm}$, respectively. The tumor is most frequently located in the distal esophagus $(54.8 \%, 17 / 31)$. Interestingly, the clinicopathologic characteristics of this tumor differ in various ethnical patient groups. For instance, the patients' median age is younger in Chinese than in non-Chinese (46years in Chinese, versus 57.5 years in non-Chinese). In Chinese patients, esophageal lymphangioma shows a predilection of upper- and middle-esophagus location (75\%, 9/12), whereas only 5 of 19 tumors (26.3\%) located in the same site in non-Chinese patients. Moreover, the tumor size is also larger in Chinese patients. Among the patients with tumor size exceeding $5 \mathrm{~cm}, 80 \%(4 / 5)$ are Chinese. Understandably, the increased detection of this rare 
Table 1 Cases of Esophageal Lymphangioma in the English Literature

\begin{tabular}{|c|c|c|c|c|c|c|c|c|c|}
\hline Case & Author & Year & Country & Gender & Age & Site & Size $(\mathrm{cm})$ & Chief Complains & Treatment \\
\hline 1 & $\begin{array}{l}\text { Watson- } \\
\text { williams [4] }\end{array}$ & 1934 & UK & Male & 61 & $L$ & NA & Chest pain, vomiting & Observation \\
\hline 2 & Schmidt [5] & 1961 & USA & NA & NA & NA & NA & NA & Autopsy \\
\hline 3 & Brady [6] & 1973 & USA & Female & 62 & L & 5 & Epigastric pain & Observation \\
\hline 4 & $\begin{array}{l}\text { Armengol-Miro } \\
{[7]}\end{array}$ & 1979 & Spain & Male & 64 & L & 1 & Epigastric pain & Snare polypectomy \\
\hline 5 & Tmamada [8] & 1980 & Japan & Male & 46 & $\mathrm{~L}$ & NA & Dysphagia, vomiting & Open surgery \\
\hline 6 & Liebert [9] & 1983 & USA & Male & 58 & L & 1.5 & Dysphagia & Snare polypectomy \\
\hline 7 & $\begin{array}{l}\text { Castellanos } \\
{[10]}\end{array}$ & 1990 & Spain & Female & 66 & M & $2 \times 1.5$ & Chest pain & Open surgery \\
\hline 8 & Yoshida [11] & 1994 & Japan & Male & 55 & M & 4 & Heart burn & Open surgery \\
\hline 9 & Suwa [12] & 1996 & Japan & Female & 52 & L & $2.2 \times 2$ & Dysphagia & Snare polypectomy \\
\hline 10 & Scarpis [13] & 1998 & Italy & Male & 64 & L & 1.5 & Epigastric pain & Snare polypectomy \\
\hline 11 & Lee [14] & 2002 & Korea & Male & 37 & $M, L$ & NA & Dysphagia & $\begin{array}{l}\text { INF a } 2 \text { a and partial } \\
\text { polypectomy }\end{array}$ \\
\hline 12 & Yoon [15] & 2004 & Korea & Male & 72 & L & $5.1 \times 2.3$ & Vomiting & Open surgery \\
\hline 13 & Saers [16] & 2005 & Germany & Female & 52 & L & 0.7 & $\begin{array}{l}\text { Dysphagia, chest pain, abdominal } \\
\text { discomfort }\end{array}$ & Endoscopic mucosal resection \\
\hline 14 & Sushil [17] & 2007 & USA & Male & 68 & L & $1.4 \times 1.4$ & Heart burn & Snare polypectomy \\
\hline 15 & Best [18] & 2008 & USA & Male & 68 & U & $3.5 \times 2.2,2 \times 1.4$ & Dysphagia & $\mathrm{CO} 2$ laser resection \\
\hline 16 & Seybt [19] & 2008 & USA & Male & 53 & $L$ & 4 & Dysphagia, regurgitation & Open surgery \\
\hline 17 & Arashiro [20] & 2010 & Japan & Female & 33 & $L$ & $1.9 \times 1.5$ & Reflux symptoms & $\begin{array}{l}\text { Endoscopic submucosal } \\
\text { dissection }\end{array}$ \\
\hline 18 & Lee [21] & 2011 & Korea & Male & 55 & M & 0.7 & NA & $\begin{array}{l}\text { Endoscopic resection with band } \\
\text { ligation }\end{array}$ \\
\hline 19 & Xue [22] & 2012 & China & Male & 58 & $M, L$ & $\begin{array}{l}10 \times 2.5 \times 1,6 \times \\
5 \times 4\end{array}$ & Dysphagia & Open surgery \\
\hline 20 & \multirow[t]{6}{*}{ Zhao [23] } & 2013 & China & Male & 35 & U & $0.8 \times 0.6$ & \multirow[t]{6}{*}{ Asymptomatic } & \multirow{6}{*}{$\begin{array}{l}\text { Dual-channel endoscopic } \\
\text { resection }\end{array}$} \\
\hline 21 & & 2013 & China & Female & 42 & M & $0.8 \times 0.5$ & & \\
\hline 22 & & 2013 & China & Male & 47 & M & $0.4 \times 0.4$ & & \\
\hline 23 & & 2013 & China & Male & 38 & M & $1.2 \times 0.7$ & & \\
\hline 24 & & 2013 & China & Male & 77 & $L$ & $0.7 \times 0.4$ & & \\
\hline 25 & & 2013 & China & Female & 50 & M & $0.8 \times 0.5$ & & \\
\hline 26 & Barbosa [24] & 2015 & Portugal & Male & 57 & $L$ & 1.2 & Asymptomatic & Observation \\
\hline 27 & Luo [25] & 2017 & China & Male & 41 & L & $6 \times 1$ & Dysphagia & $\begin{array}{l}\text { Endoscopic piecemeal mucosal } \\
\text { resection }\end{array}$ \\
\hline 28 & Zhao [26] & 2017 & China & Male & 59 & M & NA & Choking & Endoscopic mucosal resection \\
\hline 29 & $\mathrm{Hu}[27]$ & 2018 & China & Male & 46 & M & $16 \times 6 \times 4$ & Dysphagia & $\begin{array}{l}\text { Endoscopic submucosal } \\
\text { dissection }\end{array}$ \\
\hline 30 & $\operatorname{Min}[28]$ & 2018 & China & Female & 44 & M & 7 & Dysphagia & Snare electrocautery \\
\hline 31 & Present case & 2019 & China & Female & 48 & $U$ & $1.5 \times 1.2 \times 1$ & Dysphagia & $\begin{array}{l}\text { Endoscopic submucosal } \\
\text { dissection }\end{array}$ \\
\hline
\end{tabular}

UK: United Kingdom; USA: United States of America; L: Lower esophagus; M: Middle esophagus; U: upper esophagus; INF: interferon

tumor in China may be related to the widespread availability of upper endoscopy among ordinary citizens in this most populous country in the world.

Overall, clinical presentations of patients with esophageal lymphangioma are nonspecific. They may be asymptomatic or may have various chief complaints, depending upon the location and size of a tumor. Dysphagia, as shown in our case, is the most common [14, 25, 27, 28]. Other common symptoms include heartburn and epigastric pain, which may be related to coexisting 
gastropathy and reflux disease [13, 22]. There are still some tumors identified incidentally $[18,23]$.

Endoscopically the tumor is pale-pink, whitish gray, or watery yellowish, polypoid, and translucent; it is pliable when compressed by the biopsy forceps [13, 23-25]. The overlying mucosa is normal-appearing under white light endoscopy. A large tumor may be lustrous and translucent $[27,28]$. Esophageal EUS is routinely used to evaluate the size and depth of a lesion. The classical characteristics of esophageal lymphangioma under EUS manifest a honeycomb- or grid-like multi-microcystic echo pattern and the lesion may involve lamina propria and submucosal layer. Sometimes, the echo pattern may vary, according to the size of dilated lymphatic vessels $[17,20,27,28]$. EUS examination is very helpful to differentiate lymphangioma from leiomyoma, the most frequent esophageal SMT, because EUS is able to clearly exhibit the micro-cystic echo pattern and the underlying intact muscularis propria.

Microscopically, esophageal lymphangioma is characterized by localized proliferation of thin-walled, dilated lymphatic channels in various sizes, as shown in the current case. There is no dysplasia in the overlying squamous epithelium, except in 1 case reported by Scarpis et al, who described focal low-medium grade dysplasia in the squamous epithelium overlying the tumor [13]. In most cases, it is not difficult to establish the correct diagnosis based on histological features. In the cases needed to be differentiated from hemangioma, the diagnosis of lymphangioma can be confirmed by a positive immunostaining pattern in lymphatic endothelial cells for D2-40 and a negative immunoreactivity for FVIII, while the expression of CD34 is variable [1].

Different treatment modalities may be used for esophageal lymphangioma, according to the tumor size. Since the absence of published reports on malignant transformation of lymphangioma, the patient with a confirmed diagnosis of esophageal lymphangioma can be managed conservatively. A large symptomatic tumor may be resected surgically. Previously, endoscopic therapy was not used to resect esophageal lymphangioma in size of larger than $2 \mathrm{~cm}$ [17]. Nowadays, with the improvement in endoscopic methods and accumulating operative experience by endoscopists, large tumors in size up to $16 \mathrm{~cm}$ have been reported to be completely and successfully removed endoscopically without major adverse outcomes [25]. Endoscopic resection has become the treatment of choice for gastrointestinal SMT with advantages over surgery in safety, effectiveness, minimal injury, and better quality of life after resection. Numerous endoscopic treatment methods have been gradually used to resect esophageal lymphangioma, such as dual-channel endoscopic resection, endoscopic resection with ligation device, cap-assisted endoscopic mucosal resection, endoscopic mucosal resection with an electrocautery snare, laser resection and ESD $[16,18$, $23,27,28]$.

In conclusion, esophageal lymphangioma is a rare submucosal tumor and should be included in the differential diagnosis of esophageal SMT. EUS plays an important role in preoperative diagnosis and evaluation of the tumor size and depth. At present, endoscopic resection appears to be the treatment of choice for suitable patients to relieve symptoms and render a definitive histopathologic diagnosis. Histopathologic evaluation demonstrates characteristic proliferation of variably-sized lymphatic channels with auxiliary immunostaining patterns for D2-40, FVIII, and CD34.

\section{Abbreviations}

ESD: endoscopic submucosal dissection; EUS: endoscopic ultrasonography; SMT: submucosal tumor

\section{Acknowledgements}

Not applicable.

\section{Authors' contributions}

YC collected the data with $X Z$ and was the main writer of the manuscript. KX treated the patient and interpreted the data. $\mathrm{QH}$ revised and give the final approval of the version to be published.

\section{Funding}

None.

Availability of data and materials

All the data regarding the findings are available within the manuscript.

Ethics approval and consent to participate

Not applicable.

\section{Consent for publication}

Written informed consent for publication of medical information was obtained from the patient.

\section{Competing interests}

Qin Huang currently acts as an editorial board member for BMC Gastroenterology. All other authors declare that they have no competing interests.

\section{Author details}

${ }^{1}$ Department of Pathology of the Affiliated Changzhou Second People's Hospital of Nanjing Medical University, Changzhou, China. ${ }^{2}$ Department of Oncology of the Affiliated Changzhou Second People's Hospital of Nanjing Medical University, Changzhou, China. ${ }^{3}$ Department of Pathology and Laboratory Medicine of Veterans Affairs Boston Healthcare System, Harvard Medical School and Brigham and Women's Hospital, 1400 VFW Parkway, West Roxbury, MA 02132, USA.

Received: 12 May 2019 Accepted: 19 June 2019

Published online: 26 June 2019

References

1. Beham A. Lymphangioma. In: fletcher CDM, bridge JA, Hogendoorn PCW, editors. WHO classification of Tumours of soft tissue and bone. $4^{\text {th }} \mathrm{ed}$. France: International Agency for Research on. Cancer. 2013:144-5.

2. Gangl A, Polterauer P, Krepler R, Kumpan W. A further case of submucosal lymphangioma of the duodenum diagnosed during endoscopy. Endoscopy. 1980;12:188-90.

3. Huang Q, Minor MA, Weber HC. Clinical challenges and images in Gl. Diagnosis: cavernous lymphangioma of the jejunum. Gastroenterology. 2009;136(1170):465. 
4. Watson-Williams E. Specimen : Lymphangeioma of the Oesophagus. Proc R Soc Med. 1934;27:1288

5. Schmidt HW, Clagett OT, Harrison EG Jr. Benign tumors and cysts of the esophagus. J Thorac Cardiovasc Surg. 1961;41:717-32.

6. Brady PG, Milligan FD. Lymphangioma of the esophagus--diagnosis by endoscopic biopsy. Am J Dig Dis. 1973;18:423-5.

7. Armengol-Miro JR, Ramentol F, Salord J, Costa MP, Palacin A, Vidal MT. Lymphangioma of the oesophagus. Diagnosis and treatment by endoscopic polypectomy. Endoscopy. 1979;11:185-9.

8. Tamada R, Sugimachi K, Yaita A, Inokuchi K, Watanabe H. Lymphangioma of the esophagus presenting symptoms of achalasia--a case report. Jpn J Surg. 1980;10:59-62.

9. Liebert CW, Jr. Symptomatic lymphangioma of the esophagus with endoscopic resection. Gastrointest Endosc 1983; 29:225-226.

10. Castellanos D, Sebastian JJ, Larrad A, Menchen P, Senent C, Nunez JM, et al. Esophageal lymphangioma: case report and review of the literature. Surgery. 1990;108:593-4.

11. Yoshida Y, Okamura T, Ezaki T, Yano K, Kodate M. Muratal, et al. Lymphangioma of the oesophagus: a case report and review of the literature. Thorax. 1994;49:1267-8.

12. Suwa T, Ozawa S, Ando N, Shinozaki H, Tsujitsuka K, Miki H, et al. Case report: lymphangioma of the oesophagus endoscopically resected. J Gastroenterol Hepatol. 1996;11:786-8.

13. Scarpis M, De Monti M, Pezzotta MG, Sonnino D, Mosca D, Milani M. Endoscopic resection of esophageal lymphangioma incidentally discovered. Diagn Ther Endosc. 1998:4:141-7.

14. Lee BI, Kim BW, Kim KM, Song HJ, Cho SH, Choi H, et al. Esophageal lymphangiomatosis: a case report. Gastrointest Endosc. 2002;56:589-91.

15. Yoon YH, Kim KH, Baek WK, Kim JT, Son KH, Han JY, et al. Lymphangioma of the esophagus: surgical treatment. Ann Thorac Surg. 2004;78:e51-3.

16. Saers T, Parusel M, Brockmann M, Krakamp B. Lymphangioma of the esophagus. Gastrointest Endosc. 2005;62:181-4.

17. Sushil A, Aline PC, Metin O, Nadim H. Lymphangioma of the esophagus treated with endoscopic submucosal resection. J Gastroenterol Hepatol. 2007;22:284-6

18. Best SR, Coelho DH, Ahrens WA, Atez G, Sasaki CT. Laser excision of multiple esophageal lymphangiomas: a case report and review of the literature. Auris Nasus Larynx. 2008;35:300-3.

19. Seybt MW, Postma GN. Giant esophageal lymphangioma. Ear Nose Throat J. 2008;87:500

20. Arashiro M, Satoh K, Osawa H, Yoshizawa M, Nakano H, Ajibe H, et al. Endoscopic submucosal dissection of esophageal lymphangioma: a case report with a review of the literature. Clin J Gastroenterol. 2010;3:140-3.

21. Lee DG, Kim GH, Park DY, Jeong JH, Moon JY, Lee BE, et al. Endoscopic submucosal resection of esophageal subepithelial lesions using band ligation. Endoscopy. 2011:43:822-5.

22. Xue L, Guo WG, Hou J, Ge D, Chen XJ. Huge lymphangiomatosis of the esophagus. Ann Thorac Surg. 2012;93:2048-51.

23. Zhao ZF, Kuang L, Zhang N, Ma SR, Yang Z, Han X, et al. Endoscopic diagnosis and treatment of esophageal cavernous lymphangioma. Surg Laparosc Endosc Percutan Tech. 2013;23:299-302.

24. Barbosa M, Ribeiro PM, Cotter J. Oesophageal lymphangioma: an exceedingly rare tumour. BMJ Case Rep. 2015;2015.

25. Luo D, Ye L, Wu W, Zheng H, Mao X. Huge Lymphangioma of the esophagus resected by endoscopic piecemeal mucosal resection. Case Rep Med. 2017;2017:5747560

26. Zhao H, Xu W, Wang Z. Multiple submucosal masses in the esophagus: esophageal Lymphangiomatosis. Am J Gastroenterol. 2017;112:1493.

27. Hu L, Fu Kl, Tuo B, Di L, Liu X, Zhao K, et al. Endoscopic submucosal dissection of a giant esophageal lymphangioma. Endoscopy. 2018;50: E181-E3.

28. Min M, Liu Y. Lymphangioma of the esophagus. Am J Gastroenterol. 2018; 113:936.

\section{Publisher's Note}

Springer Nature remains neutral with regard to jurisdictional claims in published maps and institutional affiliations.

\section{Ready to submit your research? Choose BMC and benefit from:}

- fast, convenient online submission

- thorough peer review by experienced researchers in your field

- rapid publication on acceptance

- support for research data, including large and complex data types

- gold Open Access which fosters wider collaboration and increased citations

- maximum visibility for your research: over $100 \mathrm{M}$ website views per year

At BMC, research is always in progress.

Learn more biomedcentral.com/submissions 